\title{
Associação entre a contagem de linfócitos T CD4+ e a gravidade da neoplasia intra-epitelial cervical diagnosticada pela histopatologia em mulheres infectadas pelo HIV
}

\author{
Association between CD4+ T-cell count and intraepithelial cervical \\ neoplasia diagnosed by histopathology in HIV-infected women
}

Juliana Barroso Zimmermmann ${ }^{1}$, Victor Hugo $\mathrm{Melo}^{2}$, Lúcia Porto Fonseca de Castro ${ }^{3}$, Márcio José Martins Alves ${ }^{4}$, Sebastião Guerra Zimmermmann ${ }^{5}$, Dora Mendez Del Castillo ${ }^{6}$

\section{RESUMO}

Objetivo: avaliar a associação entre a contagem de linfócitos T CD4+ e a gravidade da neoplasia intra-epitelial cervical em pacientes HIV positivas. Métodos: estudo transversal no qual foram incluídas 87 pacientes infectadas pelo HIV, confirmado por testes sorológicos prévios. Todas eram portadoras do HPV cervical, diagnosticado por meio da reação em cadeia da polimerase. Foram realizados anamnese, exame físico e colposcopia de todas em pacientes. A biópsia do colo uterino foi realizada quando indicada pelo exame colposcópico. Os resultados histopatológicos foram classificados com neoplasia intra-epitelial de baixo grau (NIC I) ou de alto grau (NIC II e II). A associação entre a contagem de linfócitos T CD4+ e a gravidade da lesão foi verificada por meio da comparação de médias utilizando a análise da variância (ANOVA). Resultados: entre as 60 pacientes biopsiadas foram encontrados 24 casos $(40,0 \%)$ com NIC I, oito (13,3\%) NIC II, três (5\%) NIC III, 14 (23,3\%) pacientes somente com cervicite crônica e $11(18,3 \%)$ apresentando efeito citopático produzido pelo HPV, mas sem perda da polaridade celular. Isso equivale a 35 mulheres com lesão intra-epitelial de baixo grau (NIC I + HPV) $(58,3 \%)$ e $11(18,3 \%)$ com lesão intra-epitelial de alto grau (NIC II + NIC III). A associação entre a média da contagem de linfócitos T CD4+ e a gravidade da lesão intra-epitelial cervical não foi significativa ( $\mathrm{p}=0,901)$. Conclusões: não houve associação entre a contagem de linfócitos T CD4+ e a gravidade da lesão intra-epitelial do colo uterino, diagnosticada pelo exame histopatológico.

PALAVRAS-CHAVE: Neoplasia intra-epitelial cervical/patologia; Sondas DNA HPV; Neoplasias do colo do útero; Infecções por HIV; AIDS

\section{ABSTRACT}

Purpose: to evaluate association between CD4+ cell count and cervical intraepithelial lesion severity in HIV-infected women. Methods: cross-sectional study of $87 \mathrm{HIV}$-infected patients which were confirmed by previous serologic examinations. All had cervical HPV diagnosed by polymerase chain reaction (PCR). All patients underwent anamnesis, physical examinations and colposcopy. Cervix biopsy was performed when indicated by colposcopical examination. Histopathological results followed Richart's classification, adapted by Wright, and CD4+ cell count and cervical intraepithelial lesion severity association was analysed by comparison of means using analysis using analysis of variance (ANOVA).Results: among 60 biopsied women 24 were found $(40.0 \%)$ with CIN I, eight $(13.3 \%)$ with CIN II, three (5\%) with CIN III, 14 $(23.3 \%)$ with chronic cervicitis and 11 with cytopathic effect of HPV, without cell polarity loss. This corresponds to 35 $(58.3 \%)$ women with intraepithelial lesion of low grade (CIN I + HPV) and 11 (18.3\%) with intraepithelial lesion of high grade (CIN II + CIN III). There was no significant association between CD4+ cell count mean and cervical intraepithelial lesion severity $(\mathrm{p}=0.901)$. Conclusions: there was no association between CD4+ cell count and cervical intraepithelial lesion severity diagnosed by histopathological examination.

KEYWORDS: Cervical intraepithelial neoplasia/pathology; DNA Probes, HPV; Uterine cervical neoplasms; HIV infections; AIDS

Trabalho realizado no Centro de Treinamento e Referência em Doenças Infecciosas e Parasitárias Orestes Diniz (CTR-DIP) - Belo Horizonte (MG), Brasil.

1 Professora da Disciplina de Ginecologia da Faculdade de Medicina de Barbacena da Universidade Presidente Antônio Carlos - FUNJOB - Barbacena (MG), Brasil.

2 Professor Adjunto do Departamento de Ginecologia e Obstetrícia da Faculdade de Medicina da Universidade Federal de Minas Gerais - UFMG - Belo Horizonte (MG), Brasil.

3 Professora Adjunta do Departamento de Anatomia Patológica da Faculdade de Medicina da Universidade Federal de Minas Gerais - UFMG - Belo Horizonte (MG), Brasil.

4 Professor do Departamento de Epidemiologia da Faculdade de Medicina da Universidade Federal de Juiz de Fora - UFJF - Juiz de Fora (MG) - Brasil.

5 Professor Adjunto do Departamento de Cirurgia da Faculdade de Medicina da Universidade Federal de Juiz de Fora - UFJF - Juiz de Fora (MG) - Brasil.

6 Coordenadora do Núcleo de Pesquisa em Apoio Diagnóstico da Faculdade de Medicina da Universidade Federal de Minas Gerais - UFMG - Belo Horizonte (MG), Brasil.

Correspondência: Juliana Barroso Zimmermmann - Av. Rio Branco, 2406 - sala 1101 - Juiz de Fora - MG - e-mail: julianabz@uol.com.br

Recebido em: 20/10/2005 Aceito com modificaçōes em: 20/6/2006

Rev Bras Ginecol Obstet. 2006; 28(6): 345-51. 


\section{Introdução}

A neoplasia maligna do colo uterino é importante pela sua freqüência e pela fase da vida em que acomete a mulher, e acredita-se que o estado de imunocompetência do hospedeiro pode ter algum papel na evolução das lesões cervicais. O papilomavirus humano (HPV), reconhecidamente associado ao câncer cervical, penetra no organismo por meio da relação sexual, atingindo as células basais da mucosa do colo uterino. Como estas células não têm resposta eficiente aos antígenos, o HPV permanece em seu interior, sem desencadear resposta imunológica, determinando atraso em seu reconhecimento pelo sistema imune, o que facilita sua multiplicação ${ }^{1-3}$.

$O$ virus da imunodeficiência humana (HIV) não é o único responsável pelas doenças e mortes associadas à sindrome da imunodeficiência adquirida. Sabe-se que o virus suprime gradualmente a imunidade do indivíduo ao eliminar as células com o receptor T CD4+, responsáveis pela resposta imunológica humoral e celular ${ }^{1,2,4}$. Relata-se incidência aumentada de neoplasia cervical intra-epitelial (NIC) em mulheres soropositivas para o HIV, quando comparadas com a população em geral - em parte devido à baixa imunidade dessas mulheres -, com estimativa de que tais pacientes têm até dez vezes mais chance de desenvolver NIC do que aquelas não portadoras do virus ${ }^{2,4-7}$. Estudos recentes, realizados na África, encontraram freqüência significativamente aumentada de alterações celulares e maior prevalência da lesão escamosa intra-epitelial nas soropositivas, quando comparadas com as soronegativas ${ }^{8,9}$. Contudo, não foi encontrada associação entre a gravidade das neoplasias cervicais e a imunossupressão das pacientes ${ }^{9}$.

A maior prevalência do HPV no colo uterino em pacientes soropositivas para o $\mathrm{HIV}^{1,4,5} \mathrm{e}$ a imunossupressão decorrente desta infecção aumentam o risco de desenvolvimento de NIC, recomendandose estrito controle citológico, colposcópico e o uso de terapias ablativas, quando diagnosticadas as lesões intra-epiteliais ${ }^{10,11}$. Além disso, o controle imunológico dessas pacientes é citado como um aliado na prevenção destas neoplasias, já que se acredita que exista associação entre a contagem de linfócitos T CD4+, a carga viral do HIV e a persistência do HPV ${ }^{12-14}$.

Com base no exposto, o objetivo do presente estudo foi avaliar a associação entre a contagem de linfócitos T CD4+ e a gravidade das NIC, diagnosticadas no estudo histopatológico de biópsias de pacientes soropositivas para o HIV.

\section{Métodos}

Foi realizado estudo transversal envolvendo 87 pacientes atendidas no período de julho de 2002 a outubro de 2003 oriundas do Centro de Treinamento e Referência em Doenças Infecciosas e Parasitárias Orestes Diniz (CTR-DIP), vinculado ao Hospital das Clínicas da UFMG e à Prefeitura Municipal de Belo Horizonte. Todas as pacientes tiveram diagnóstico confirmatório da infecção pelo HIV, conforme o protocolo do Ministério da Saúde. $\mathrm{Na}$ primeira amostra sorológica coletada eram realizados dois testes para o rastreamento inicial, o ELISA (enzyme-linked immunosorbent assay) e o MEIA (immunoenzymatic analysis methods). Caso um destes testes fosse positivo, ou indeterminado, utilizava-se o Western blot ou a imunofluorescência para a confirmação sorológica. Verificada a positividade sorológica, outra amostra era colhida com intervalo de um mês para a realização de outro ELISA e MEIA. A paciente que apresentasse um dos testes positivo tinha confirmado seu diagnóstico sorológico de infecção pelo HIV.

Os critérios de inclusão foram: ser portadora do HIV, ter idade maior ou igual a 18 anos e ser portadora do HPV genital. Foram excluídas as gestantes.

Para avaliar o número de pacientes necessárias para responder ao objetivo do estudo, foi realizado o cálculo do tamanho da amostra, utilizando o programa Epi-Info, versão 6.04b. Considerando a possibilidade de NIC de 35\% na população soropositiva para o HIV, com erro alfa de $5 \%$ e precisão de $10 \%$, estimou-se ser necessário o recrutamento de 87 pacientes soropositivas para o HIV. Neste estudo a interpretação da precisão foi a seguinte: existe uma probabilidade de 90\% de que o intervalo inclua o real efeito clínico da intervenção sob investigação.

A detecção da presença do DNA HPV foi realizada pela reação em cadeia de polimerase (PCR). Esta técnica multiplica o DNA do material em estudo. Assim, mesmo que determinada célula contenha somente uma cópia viral, ao fim do procedimento mais de um milhão de seqüências de DNA estarão presentes em um único tubo. Com isso, a concentração de DNA-alvo cresce, permitindo a identificação do HPV ${ }^{1,2}$.

As pacientes eram entrevistadas e, caso concordassem com a coleta da amostra para a detecção do DNA HPV, respondiam ao questionário do protocolo de atendimento ginecológico previamente definido. Após a anamnese eram submetidas a exame ginecológico de rotina, com inspeção da genitália externa e, após a colocação do espéculo, colhia-se 
material cervical para a realização da PCR. Este procedimento era realizado raspando-se o colo uterino com espátula de madeira (Ayre) e, após quebrá-la, introduzia-se o terço com a parte coletada em tubo esterilizado contendo $1 \mathrm{~mL}$ de soro fisiológico. Amostras da endocérvix (escova) e ectocérvix (espátula) também eram coletadas para a realização da citologia oncótica. $\mathrm{O}$ material para a $\mathrm{PCR}$ era enviado ao Núcleo de Pesquisa em Apoio Diagnóstico (Nupad) para processamento e diagnóstico, e a amostra citológica para o Departamento de Anatomia Patológica, ambos da Faculdade de Medicina da UFMG.

A colposcopia era realizada rotineiramente, utilizando-se o aparelho de marca Liesegang, modelo padrão, aplicando-se ácido acético a 3\%, solução de Schiller e bissulfito a 5\%. A terminologia colposcópica seguida foi a da Federação Internacional de Patologia Cervical ${ }^{15}$. Os achados colposcópicos considerados alterados foram: epitélio acetobranco, pontilhado, mosaico, parcialmente iodo-positivo, iodo-negativo e vasos atípicos. Caso fosse identificada área alterada no colo uterino, efetuava-se a biópsia sob visão colposcópica, utilizando a pinça de Gaylor-Medina. A seguir, o material era fixado em formol a $10 \%$ e enviado ao laboratório. Eram realizados cortes dos blocos de parafina com $5 \mu \mathrm{m}$ de espessura que, a seguir, eram corados com hematoxilina-eosina. As lâminas foram examinadas em microscópio binocular, marca Leica, modelo DMLB, de três cabeças. O material biopsiado foi revisado por um único patologista.

As categorias histopatológicas foram assim definidas: a) NIC grau I (NIC I): perda de polaridade celular, ausência da estratificação epitelial normal e hiperplasia da camada basal que não excedia um terço da espessura do epitélio; b) NIC grau II (NIC II): perda de polaridade celular, ausência da estratificação epitelial normal e hiperplasia da camada basal que atingia até dois terços da espessura do epitélio; c) NIC grau III (NIC III): as lesões apresentavam mais de dois terços do epitélio acometidos por células com pleomorfismo acentuado, cromatina granulosa e nucleomegalia acentuada. Neste grupo também foram incluídas as lesões que acometiam todo o epitélio, porém sem sinais de invasão; d) infecção pelo HPV: caracterizada pela paraceratose, discariose, hiperceratose, núcleos atípicos, bi e multinucleação, papilomatose e coilocitose; e) cervicite crônica: lesões com infiltrado inflamatório mononuclear com tecido de granulação e fibrose do estroma. Foi utilizada classificação histopatológica que associa o diagnóstico de NIC com as lesões intra-epiteliais de baixo e alto grau ${ }^{14}$.

A contagem de linfócitos T CD4+ foi realizada pelo Laboratório Central do Hospital das Clínicas da UFMG, utilizando-se a citometria de fluxo, técnica que utiliza anticorpos monoclonais e fornece a contagem absoluta de células pela emissão de luz. Considerou-se o resultado mais próximo da primeira consulta ginecológica.

Os dados foram digitados e armazenados no software Epi-Info, versão 6.04b, e exportados para o software SPSS, versão 8.0. Os teste estatístico utilizado foi ANOVA para a comparação entre as contagens médias dos linfócitos T CD4+. Essa análise é uma das técnicas mais utilizadas em estatística quando o objetivo é comparar a média de várias populações ou subpopulações, e independe do tamanho e composição dos grupos. Para o cálculo estatístico a classificação histopatológica foi reduzida a três categorias: ausência de neoplasia; lesões intra-epiteliais de baixo grau, nas quais foram incluídas as NIC de grau I e as lesões induzidas pelo HPV; lesões intra-epiteliais de alto grau, incluindo-se as NIC de grau II e III ${ }^{14}$. Foi considerado o nível de significância de $5 \%(p<0,05)$. Este estudo foi aprovado pelo Comitê de Ética em Pesquisa da Universidade Federal de Minas Gerais (Parecer 085/2002). Todas as pacientes assinaram o termo de consentimento livre e esclarecido.

\section{Resultados}

Das 87 pacientes que concordaram em participar do estudo, 32 apresentaram colposcopia normal. Todas as 55 pacientes com colposcopia alterada foram biopsiadas. Outras cinco pacientes, embora com colposcopia normal, apresentavam grande área de ectopia e também foram biopsiadas, para a realização posterior de cauterização. Assim, foram biopsiadas 60 pacientes.

A idade destas pacientes variou de 18 a 64 anos, com mediana de 30 anos e média de $31,5 \pm 8,5$ anos, sendo $43,3 \%$ solteiras. A idade do início da atividade sexual variou de 12 a 25 anos, com mediana de 17 anos e média de $17,3 \pm 2,8$ anos, sendo que $67,8 \%$ encontravam-se sexualmente ativas e 26,7\% tinham antecedentes de DST. Quanto ao número de parceiros sexuais em toda a vida, $69,4 \%$ apresentaram de um a três, com mediana de 3 parceiros. O tabagismo foi verificado em 35\% e a grande maioria das pacientes fazia uso de medicação anti-retroviral $(80,5 \%)$.

Das amostras citológicas colhidas, três foram desconsideradas por apresentar material inadequado para análise, devido a ressecamento. Encontraram-se 53,6\% das pacientes com citologia normal, 20,2\% com efeitos citopáticos do HPV, $17,9 \%$ com NIC I), $7,1 \%$ com NIC II e $1,2 \%$ com 
NIC III. Os resultados citológicos são apresentados na Tabela 1.

Entre as 60 pacientes biopsiadas foram encontradas 24 com NIC I $(40,0 \%)$, oito $(13,3 \%)$ com NIC II, três (5\%) com NIC III, 14 (23,3\%) pacientes somente com cervicite crônica e 11 $(18,3 \%)$ apresentando efeito citopático produzido pelo HPV, mas sem perda da polaridade celular. Isso equivale, segundo a classificacão de Wright ${ }^{14}$, a 35 (58,3\%) mulheres com lesão intra-epitelial cervical de baixo grau (NIC I + HPV) e 11 (18,3\%) com lesão intra-epitelial cervical de alto grau (NIC II + NIC III), conforme ilustrado na Tabela 1. A presença de HPV isoladamente, ou associado a NIC, foi diagnosticada pela histopatologia em 41 $(68,3 \%)$ pacientes.

A contagem de células T CD4+ escolhida foi a mais próxima da consulta. Para a associação entre a contagem de linfócitos T CD4+ e o resultado histopatológico, utilizou-se a classificação já mencionada ${ }^{14}$. As pacientes com diagnóstico histopatológico de lesão intra-epitelial de alto grau apresentaram contagem média de linfócitos T CD4+ de 339 células $/ \mathrm{mm}^{3}$ no sangue, e aquelas com diagnóstico histopatológico de lesão intra-epitelial de baixo grau apresentaram contagem média de 276,5 células $/ \mathrm{mm}^{3}$ no sangue. As pacientes que não tinham diagnóstico de lesão intra-epitelial cervical apresentaram contagem média de linfócitos T CD4+ de 270,9 células $/ \mathrm{mm}^{3}$. Para a comparação das médias de contagem das células CD4+ dos três grupos pesquisados (ausência de lesão, lesão de alto grau e de baixo grau) foi realizada análise da variância (ANOVA), não tendo sido encontrada diferença significante $(\mathrm{p}=0,901)$, conforme ilustrado na Tabela 2.

\section{Discussão}

As mulheres com imunodeficiência têm maiores chances de desenvolver neoplasias intraepiteliais cervicais e vaginais ${ }^{4-9,11,16}$. Além disso, alguns estudos demonstram associação entre a gravidade da neoplasia intraepitelial cervical e a imunossupressão induzida pelo HIV ${ }^{14}$. Tais resultados foram também verificados em estudo italiano com 242 pacientes, comparando-se pacientes soropositivas e negativas para o HIV, no qual foi verificado que as lesões displásicas cervicais são significativamente mais freqüentes e agressivas nas soropositivas (38\%) que nas soronegativas $(12 \%)(\mathrm{p}<0,001)^{17}$.

Estudo realizado na Universidade da Califórnia ${ }^{18}$ verificou que o risco de neoplasia intraepitelial cervical é maior em pacientes com contagem de linfócitos T CD4+ inferior a 200 células $/ \mathrm{mm}^{3}$. Entretanto, apesar de o grau de imunossupressão poder contribuir para o desenvolvimento da neoplasia intraepitelial nas pacientes soropositivas, ele não interfere na gravidade, quando a neoplasia já encontra-se instalada ${ }^{19}$. No nosso estudo não verificamos a associação entre imunossupressão e gravidade da lesão $(p=0,98)$, ou seja, a contagem de linfócitos T CD4+ não se mostrou estatisticamente diferente entre as pacientes sem neoplasia intra-epitelial cervical ou aquelas com neoplasia de baixo ou alto grau. Outros autores também

Tabela 1 - Resultados citológicos e histopatológicos das pacientes estudadas

\begin{tabular}{|c|c|c|c|c|}
\hline Descrição da lesão & $\begin{array}{l}\text { Resultado } \\
\text { (n) }\end{array}$ & $\begin{array}{c}\text { Histopatológico } \\
(\%)\end{array}$ & $\begin{array}{l}\text { Resultado } \\
\text { (n) }\end{array}$ & $\begin{array}{c}\text { Citológico } \\
(\%)\end{array}$ \\
\hline $\mathrm{NICI}$ & 24 & 40,0 & 15 & 17,9 \\
\hline $\mathrm{NIC} \|$ & 8 & 13,3 & 6 & 7,1 \\
\hline $\mathrm{NIC} \mathrm{III}$ & 3 & 5,0 & 1 & 1,2 \\
\hline Papilomavírus humano & 11 & 18,3 & 17 & 20,2 \\
\hline Achados normais e benignos & 14 & 23,3 & 45 & 53,6 \\
\hline Total & 60 & 100 & $57^{*}$ & 100 \\
\hline
\end{tabular}

NIC: Neoplasia intra-epitelial cervical.

*Três citologias foram consideradas inadequadas para avaliação.

Tabela 2 - Associação entre a contagem de linfócitos T CD4+ e o resultado histopatológico, subdivido em três categorias.

\begin{tabular}{|c|c|c|c|c|}
\hline \multirow{2}{*}{$\begin{array}{l}\text { Resultado histopatológico } \\
\text { Classificação de Wright }\end{array}$} & \multicolumn{4}{|c|}{ Contagem de linfócitos T CD4+ } \\
\hline & Mínimo & Máximo & Média & Desvio padrão \\
\hline Ausência de neoplasia & 12 & 1305 & 270,96 & 258,52 \\
\hline LSIL & 4 & 748 & 276,52 & 187,32 \\
\hline HSIL & 57 & 821 & 339,0 & 254,07 \\
\hline
\end{tabular}

LSIL: lesão intra-epitelial de baixo grau; HSIL: lesão intra-epitelial de alto grau. ANOVA: $p=0,901$

Rev Bras Ginecol Obstet. 2006; 28(6): 345-51. 
não verificaram associação entre a contagem de linfócitos T CD4+ e a gravidade da neoplasia intra-epitelial cervical ${ }^{2,20}$. Estudo avaliando 134 pacientes soropositivas para o HIV, submetidas a biópsia do colo uterino, não encontrou associação significante entre a contagem de linfócitos $\mathrm{T}$ CD4+ e a gravidade da neoplasia intra-epitelial cervical $^{21}$. Outros autores, embora utilizando resultados citológicos ao invés de histopatológicos, como no nosso estudo, também não verificaram associação entre o grau de NIC e a contagem de linfócitos T CD4+22.

Deste modo, embora existam resultados divergentes na literatura, atualmente a maioria aponta para a não associação entre a gravidade da neoplasia cervical e a imunossupressão, especialmente após o advento da HAART (terapia anti-retroviral de alta potência). Neste contexto, estudo realizado na França com 121 mulheres soropositivas para o HIV, tratadas previamente por apresentarem algum grau de neoplasia cervical, verificou que a HAART demonstrou efeito protetor para recorrência de neoplasia cervical ( $R R=0,3$; IC a 95\%: 0,1-0,7), inclusive para as lesões intra-epiteliais cervicais de alto grau $(\mathrm{RR}=0,2 \text {; IC a 95\%: 0, 1-0,7 })^{23}$. Acredita-se que a medicação anti-retroviral, especialmente a de alta potência, possa impedir a progressão das neoplasias cervicais. Outro estudo, envolvendo 485 pacientes soropositivas para o HIV, verificou que a HAART reduziu o risco de neoplasia por restaurar a imunidade, ou seja, melhorar a resposta imunológica das pacientes ${ }^{24,25}$. Neste estudo, 80,5\% das pacientes faziam uso desta medicação.

Acreditamos que essa alta freqüência de pacientes em uso de terapia anti-retroviral possa ser uma das responsáveis pelos nossos resultados, pois ao incrementar a resposta imunológica, a terapia anti-retroviral aumenta os niveis de linfócitos T CD4+ e impede a progressão das neoplasias cervicais. Supõe-se que os efeitos anti-tumorais diretos da terapia anti-retroviral possam estar associados às ações específicas dos inibidores de proteases incluídos nos esquemas terapêuticas, como é o caso do ritonavir, nelfinavir, indinavir e saquinavir. Estas medicações têm mostrado diversos efeitos bloqueadores celulares, além da reprodução do HIV, que podem interferir no mecanismo da proliferação celular nas lesões intra-epiteliais cervicais ${ }^{25}$. Neste estudo, os inibidores de proteases foram usados em 57,3\% dos esquemas de tratamento. Apesar disso, até o momento ainda não se obteve redução significativa dos casos de câncer de colo uterino desde a introdução da HAART em 1996 26-29.

Outro ponto que precisa ser mencionado é que a resposta imunológica é muito complexa, e não deve ser avaliada apenas pela contagem de linfócitos T CD4+, já que se observa diminuição dos macrófagos, neutrófilos, células natural killer e até da expressão do interferon gama neste grupo de pacientes ${ }^{30}$. Por isso, o mecanismo imunológico cervical local, representado por células apresentadoras de antígenos, as células de Langerhans, pode ser importante na progressão destas neoplasias ${ }^{31}$. Cita-se que as células de Langerhans exercem papel fundamental como células apresentadoras de antígenos estranhos aos linfócitos T-CD4+. Deste modo, a progressão da infecção pelo virus HPV pode estar associada com alterações das células de Langerhans, do epitélio escamoso das mucosas ${ }^{32,33}$.

Por outro lado, a história natural das neoplasias intra-epiteliais cervicais mostra que se trata de processo multifatorial, em que o papilomavirus humano é necessário, mas não suficiente, para ocasionar o aparecimento da lesão. Desse modo, vários fatores poderão exercer papel importante tanto na inicialização como na evolução das lesões, como o tabagismo, os contraceptivos hormonais, a paridade e a dieta. Outras doenças sexualmente transmissiveis associadas ao HPV (como a clamidiose e o herpes vírus) poderão ter papel facilitador na evolução dessas neoplasias ${ }^{7}$. Exemplo dessa interação é que o tabagismo pode ter papel modulador da resposta imunológica por meio da redução da contagem de células de Langerhans ${ }^{33}$. No presente estudo, 35\% das pacientes biopsiadas eram fumantes e 26,7\% já tinham apresentado outras doenças sexualmente transmissiveis, fatores estes que podem prejudicar a apresentação do antígeno ao sistema imunológico, o que pode estar associado a evolução e gravidade das neoplasias cervicais, independente da contagem de linfócitos T CD4+.

Apesar de nossa amostragem estar associada a uma precisão de $10 \%$, nossos resultados são concordantes com a literatura, principalmente com os estudos que incluem a terapia anti-retroviral. Percebe-se que a história natural das neoplasias intra-epiteliais cervicais depende de inúmeros fatores e que todos precisam ser avaliados e pesquisados, a fim de se definir o real papel da resposta imunológica na redução ou progressão dessas lesões. 


\section{Referências}

1. Campos RR, Melo VH, Del Castilho DM, Nogueira $\mathrm{CPF}$. Prevalência do papilomavirus humano e seus genótipos em mulheres portadoras e não-portadoras do vírus da imunodeficiência humana. Rev Bras Ginecol Obstet. 2005;27(5):248-56

2. Souza NST, Melo VH, Castro LPF. Diagnóstico da infecção pelo HIV em lesões do colo do útero em mulheres HIV+: acuidade da histopatologia. Rev Bras Ginecol Obstet. 2001;23(6):355-61.

3. Fausch SC, Da Silva DM, Rudolf MP, Kast WM. Human papillomavirus virus-like particles do not activate Langerhans cells: a possible immune escape mechanism used by human papillomaviruses. J Immunol. 2002;169(6):3242-9.

4. De Sanjose S, Palefsky J. Cervical and anal HPV infections in HIV positive women and men. Virus Res. 2002;89(2):201-11.

5. Ahdieh L, Klein RS, Burk R, Cu-Uvin S, Schuman P, Duerr A, et al. Prevalence, incidence, and type-specific persistence of human papillomavirus in human immunodeficiency virus (HIV)-positive and HIV-negative women. J Infect Dis. 2001;184(6):682-90.

6. Serraino D, Piselli P, Scognamiglio P. Viral infections and cancer: epidemiological aspects. J Biol Regul Homeost Agents. 2001;15(3):224-8.

7. Ahmed AM, Madkan V, Tyring SK. Human papillomaviruses and genital disease. Dermatol Clin. 2006;24(2):157-65.

8. Mbizvo EM, Msuya SE, Stray-Pedersen B, Chirenje MZ, Hussain A. Cervical dyskaryosis among women with and without HIV: prevalence and risk factors. Int J STD AIDS. 2005;16(12):789-93.

9. Moodley M, Garib R. The significance of human papillomavirus infection detected by cervical cytology among women infected with the human immunodeficiency virus. J Obstet Gynaecol. 2004;24(8):903-6.

10.Nappi L, Carriero C, Bettocchi S, Herrero J, Vimercati A, Putignano G. Cervical squamous intraepithelial lesions of low-grade in HIV-infected women: recurrence, persistence, and progression, in treated and untreated women. Eur J Obstet Gynecol Reprod Biol. 2005;121(2):226-32.

11.Chen MJ, Wu MY, Yang JH, Chao KH, Yang YS, Ho HN. Increased frequency of genital human papillomavirus infection in human immunodeficiency virus-seropositive Taiwanese women. J Formos Med Assoc. 2005;104(1):34-8.

12.Strickler HD, Burk RD, Fazzari M, Anastos K, Minkoff $\mathrm{H}$, Massad LS, et al. Natural history and possible reactivation of human papillomavirus in human immunodeficiency virus-positive women. J Natl Cancer Inst. 2005;97(8):577-86.

13.Wright TC Jr, Ellerbrock TV, Chiasson MA, Van Devanter N, Sun XW. Cervical intraepithelial neopla- sia in women infected with human immunodeficiency virus: prevalence, risk factors, and validity of Papanicolaou smears. New York Cervical Disease Study. Obstet Gynecol. 1994;84(4):591-7.

14. Melo VH, Araújo ACL, Rio SMP, Castro LPF, Azevedo AA, Castro MM. Problemas ginecológicos mais freqüentes em mulheres soropositivas para o HIV. Rev Bras Ginecol Obstet. 2003;25(9):661-6.

15. Calore EE, Pereira SM, Cavaliere MJ. Progression of cervical lesions in HIV-seropositive women: a cytological study. Diagn Cytopathol. 2001;24(2):117-9.

16. Soncini E, Condemi V. Intraepithelial cervical carcinoma and HIV. Prevalence, risk factors and prevention strategies. Minerva Ginecol. 2003;55(1): 51-5.

17.Palefsky JM, Minkoff H, Kalish LA, Levine A, Sacks HS, Garcia P, et al. Cervicovaginal human papillomavirus infection in human immunodeficiency virus-1 (HIV) positive and high-risk HIV-negative women. J Natl Cancer Inst. 1999;91(3):226-36.

18. Sopracordevole F, Campagnutta E, Parin A, Vaccher E, Volpe R, Scarabelli C. Squamous intraepithelial cervical lesions in human immunodeficiency virus-seropositive women. J Reprod Med. 1996;41(8):586-90.

19.Cardillo M, Hagan R, Abadi J, Abadi MA. CD4 T-cell count, viral load, and squamous intraepithelial lesions in women infected with the human immunodeficiency virus. Cancer. 2001;93(2):111-4.

20.Araújo ACL, Melo VH, Castro LPF, Guimarães MDC, Aleixo AW, Silva ML Associação entre a carga viral e os linfócitos T CD4+ com as lesões intra-epiteliais do colo uterino em mulheres infectadas pelo vírus da imunodeficiência humana. Rev Bras Ginecol Obstet. 2005;27(3):106-11.

21.Coelho RA, Facundo MKF, Nogueira AL, Sakano CRSB, Ribalta JCL, Baracat EC. Relação entre diagnóstico citopatológico da neoplasia intra-epitelial cervical e índices de células CD4+ e de carga viral em pacientes HIV- soropositivas. Rev Bras Ginecol Obstet. 2004;26(2):97-102.

22.Heard I, Potard V, Foulot H, Chapron C, Costagliola D, Kazatchkine MD. High rate of recurrence of cervical intraepithelial neoplasia after surgery in HIV-positive women. J Acquir Immune Defic Syndr. 2005;39(4):412-8.

23.Delmas MC, Larsen C, van Benthem B, Hamers FF, Bergeron C, Poveda JD, et al. Cervical squamous intraepithelial lesions in HIV-infected women: prevalence, incidence and regression. European Study Group on Natural History of HIV Infection in Women. AIDS. 2000;14(12):1775-84.

24.Monini P, Sgadai C, Toschi E, Barillari G, Ensoli B. Antitumor effects of antiretroviral therapy. Nat Rev Cancer. 2004;4(11):861-75.

25.Piketty C, Kazatchkine MD. Human papillomavirus-

Rev Bras Ginecol Obstet. 2006; 28(6): 345-51. 
related cervical and anal disease in HIV-infected individuals in the era of highly active antiretroviral therapy. Curr HIV/AIDS Rep. 2005;2(3):140-5.

26. Bower M, Palmieri C, Dhillon T. AIDS-related malignancies: changing epidemiology and the impact of highly active antiretroviral therapy. Curr Opin Infect Dis. 2006;19(1):14-9.

27.Torre D, Speranza F, Martegani R. Impact of highly active antiretroviral therapy on organ-specific manifestations of HIV-1 infection. HIV Med. 2005;6(2):66-78.

28. May T, Lewden C, Bonnet F, Heripret L, Bevilacqua S, Jougla E, et al. Causes and characteristics of death among HIV-1 infected patients with immunovirologic response to antiretroviral treatment. Presse Med. 2004;33(21):1487-92.

29. Kobayashi A, Greenblatt RM, Anastos K, Minkoff H, Massad LS, Young M, et al. Functional attributes of mucosal immunity in cervical intraepithelial neoplasia and effects of HIV infection. Cancer Res.
2004;64(18):6766-74.

30.Uchimura NS, Ribalta JC, Focchi J, Simoes MJ, Uchimura TT, Silva ES. Evaluation of Langerhans' cells in human papillomavirus-associated squamous intraepithelial lesions of the uterine cervix. Clin Exp Obstet Gynecol. 2004;31(4):260-2.

31. Giannini SL, Hubert P, Doyen J, Boniver J, Delvenne P. Influence of the mucosal epithelium microenvironment on Langerhans cells: implications for development of squamous intraepithelial lesions of the cervix. Int J Cancer. 2002;97(5):654-9.

32.Levi G, Feldman J, Holman S, Salarieh A, Strickler $\mathrm{HD}$, Alter S, et al. Relationship between HIV viral load and Langerhans cells of the cervical epithelium. J Obstet Gynaecol Res. 2005;31(2):178-84.

33.Barton SE, Maddox PH, Jenkins D, Edwards R, Cuzick J, Singer A. Effect of cigarette smoking on cervical epithelial immunity: a mechanism for neoplastic change? Lancet. 1988;2(8612):652-4. 